\title{
ORGANIZAÇÃO SOCIAL E MITOLOGIA ENTRE OS TIMBIRA DE LESTE
}

\author{
MARIA ISAURA PEReIRA DE QUEIROZ
}

\section{INTRODUÇĀO}

Originários do mêdo ou do desejo de explicar os fenômenos naturais que rodeiam o homem, provenientes de fantasias da imaginação, ou registro de antiquíssimos fatos, existem os mitos em tôdas as culturas e civilizaçōes. Buscou-se durante algum tempo qual a sua proveniência, mas êste problema foi abandonado. A dificuldade em determinar as doses dêste ou daquele fator no seu nascimento; a compreensão de que não são apenas meras histórias ou sobrevivências do passado; a descoberta de que, como os costumes, como os instrumentos da cultura material, também os mitos migram; a noção de que desempenham uma função no conjunto da cultura em seu momento atual, fêz com que fôsse deixado de lado o esclarecimento da questão "por que existem"? Em seu lugar, procura-se investigar que papel tem - mito dentro de uma sociedade, tenta-se estudá-lo "em sua dinâmica, isto é, em relação com a atualidade social." (1)

Esta orientação é relativamente recente e encontra dificuldades para ser aplicada. Em geral, os pesquisadores se ocupam em recolher os textos miticos sem indicar quando, nem como, nem por quê, nem por quem são narrados, tomando dificil destrinchar o papel que desempenham na vida social. É o que se dá com o livro de Nimuendajú sôbre os Timbira de Leste, no qual também a excessiva preocupaçäo com a imparcialidade e com a objetividade da descrição abafou tanto a espontaneidade, quanto a coleta de elementos qualitativos que os colorissem. O modo impessoal, super-ordenado e

(16) Inocencla, edição citada; carta de Taunay a Azevedo Castro, p. vil. 
frio da exposição dificulta a plena compreensão do funcionamento da cultura como um todo, apagando as indicaçōes sôbre o que se poderia chamar de seu "clima", tão importante no esclarecimento dos ideais e dos valôres. Foi com esfôrço, respigando aqui e ali na narrativa tão classificada e tão bem dividida de Nimuendajú, que se tentou chegar a uma compreensão do "espirito" da cultura Timbira, e da função dos mitos com relação a ela.

Apresentaremos primeiramente, de forma resumida, os traços principais da cultura Timbira, para em seguida abordarmos sua mitologia.

\section{ORGANIZAÇÃO SOCIAL DOS TIMBIRA}

Os Timbira de Leste, estudados por Nimuendajú, pertencem à família Gê e abarcam quinze tribos diferentes, que se reconhecem umas às outras como parentes e membros do mesmo povo, sendo para êles o sinal visível do parentesco o fato de todos os individuos cortarem o cabelo da mesma maneira, usarem grandes discos distendendo o lóbulo das orelhas, disporem as casas da aldeia em circulo e possuirem, como esporte predileto, a corrida de troncos. (2) Habitam êstes indigenas ao norte $\mathrm{e}$ a leste do rio Tocantins, espalhando-se por tôda a bacia do Gurupi, do baixo e médio Pindaré, do baixo Grajaú e do baixo Mearim. A tribo mais estudada por Nomuendajú foi a dos Ramko'kamekra, mas a semelhança da organização com as demais permitiu a generalização da descrição para tôdas, indicando o autor as variantes que por acaso ocorressem.

Possuem estas tribos uma organização social complicada e os indivíduos pertencem a grande cópia de associaçōes, além da familia e das classes de idade: sociedades da estação festiva, metades de terreiro, metades da estação chuvosa, etc. etc. A execução do cerimonial constitui sua preocupação máxima : "... o cerimonial é da maior importância, absorvendo grande parte do tempo e da energia dos individuos. Ao mesmo tempo é tão predominantemente secular que considerá-lo como parte de uma religião é violentar os fatos". (3)

Através do cerimonial, compreendemos como são fortes os laços que prendem os individuos aos diferentes grupos e associaçōes; o lugar dêles durante a festa não é marcado pelo fato de pertencerem a determinada familia ou terem certo status na hierarquia tribal, e sim pelo fato de pertencerem a uma determinada associação - a dos Jaguar, dos Agutí, dos Mascarados, dos Falcōes, etc. Ninguém pode se furtar, sob nenhum pretexto, de participar das diferentes fases de uma festa; brigas e ressentimentos devem ser postos inteiramente de lado para que os inimigos de ontem possam hoje concorrer ao cerimonial em vias de desenvolvimento. (4)

(1) Schaden, Egon 1946, p. 15.

2) Nimuendaju, Kurt, 1946, p. 12.

(4) Id., 1946, p. 129. 
Se os laços grupais são assim apertados, os laços familiares, - especialmente os da familia grande, - não o são menos, a ponto da maior afronta entre os Timbira consistir em dizer a alguém, abertamente, que "não tem parentes". Tais laços dão ao indivíduo sentimentos de segurança e de proteção, pois é à familia grande que incumbe a defesa de seus membros dentro da tribo, cabendo a ela também indenizaçāo tôdas as vêzes que uma falta ou um crime é cometido contra êles. Durante disputas é, pois, frequiente um individuo ameaçar a outro dizendo: "Olhe que minha familia é muito numerosa..." (5)

Existe na sociedade Timbira uma regulamentaçāo rigorosa da cooperaçāo e da competição intra-tribal, ambas inteiramente desviadas do plano individual, - em que seriam influenciadas mais de perto pelos sentimentos, pelos afetos, pela emotividade, - para o plano grupal, em que a individualidade é ofuscada pela obediência e pela submissão que o individuo deve às associações a que pertence.

No caso da competição, por exemplo, que existe tanto no cerimonial quanto no setor esportivo, indivíduos não se opōem a individuos, mas grupos se opōem a grupos. No cerimonial, a sociedade dos Jaguar e dos Agutí sāo contrárias uma à outra; os Mascarados são aliados dos Agutí; os Falcōes são adversários dos Patos, etc., mas tôda a disputa é prevista e ordenada, desenvolvendo-se segundo o ritual existente. (6) No setor esportivo existem as corridas de troncos, esporte favorito e característico dos Timbira, no qual se empenham tanto homens quanto mulheres; os homens se dividem de acôrdo com classes de idade, competindo uma mais môça com outra mais velha, (7) ou de acôrdo com as "metades de terreiro", (8) ou ainda segundo as diferentes sociedades masculinas; (9) as mulheres competem divididas em "metades de terreiro", ou de acôrdo com o parentesco que as liga às diversas classes de idade masculinas. (10)

A competição puramente individual foi desviada para os passatempos e canalizada de maneira a se tornar o menos prejudicial possivel; restringe-se aos jogos de destreza principalmente. Existe o krústak, por exemplo, jôgo de meninos, no qual os competidores disparam suas flechas de maneira tal que deslizem rente ao chão, sendo vencedora a flecha que fôr mais longe. Ou também o jôgo mais perigoso dos adultos, em que um guerreiro desafia um grupo a feri-lo com suas flechas e, sob o arremêsso simultâneo delas, furta-se hàbilmente para nāo ser tocado por nenhuma, sendo considerado vencedor e dono de tôdas as flechas arremessadas se conseguir sair sem arranhöes. (11)

(5) Id, 1946, p. 84 .

(7) Id., 1946, pp. 138, 140, 185

(8) Id.; 1946, pp. 138, 40.

(9) Id.; 1946, p. 140 .

(1i) Nimuendajú, Kurt, 1946, p. 161. 
A cooperação também é da alçada de grupos: não se apela para o auxilio individual, mas para o auxilio das associações e dos grupos de idade. Se alguém tem necessidade de ajuđa para a construção de nôvo rancho, para a derrubada, para a colheita, dirige-se aos mais velhos da tribo, que transmitem o pedido a qualquer das associaçōes ou aos chefes de classes de idade; "todo o grupo se muda, por vários dias, para a roça de quem pediu auxílio, dançando metade do tempo e empregando o resto no trabalho" (9). O que lembra bastante o mutirão caboclo.

A direção da comunidade cabe ao Conselho de Anciāos, composto de individuos cujas classes de idade deixaram de pertencer ao quadro ativo dos esportistas e que não participam mais, portanto, das corridas de troncos; os problemas quotidianos, a escolha das festas, tudo é resolvido em reuniōes dêste conselho. O chefe da taba é o anciāo que provou qualidades de conciliador e de diplomata, cujo papel consiste em acabar com as brigas e conseguir o acôrdo das partes em litigio. (12)

Nem os chefes nem o conselho têm encargo de punição; o crime, que acarreta sempre disputa entre familias e sociedades, é resgatado mediante indenização. O acôrdo é conseguido pela intervenção ou do anciāo, ou do conselho e, se o poder de persuasão dêstes não é suficiente, recorre-se à autoridade quer dos parentes, quer dos companheiros de classe de idade, quer dos membros da mesma sociedade - o que mais uma vez indica o papel preponderante dos diferentes grupos na manutenção da harmonia interna da taba, seu pêso sôbre a consciência individual e a submissão que exige das pessoas.

Pela regulamentação tão estrita da competição e da cooperação, deduz-se que a organização social dos Timbira se orientou de maneira a incrementar ao máximo o companheirismo, a camaradagem, a solidariedade entre seus membros, mesmo de sexo diferente. De fato, a coerção de um individuo sôbre os outros é considerada odiosa, seja do homem sôbre o homem, seja do homem sôbre a mulher. "Se uma jovem ou uma mulher diferem em opiniāo de um homem e o acôrdo se torna impossível, a questão é abandonada; a zanga do homem, e muito mais uma tentativa de coerção de sua parte, seriam tidas como atitudes mesquinhas e ridiculas". (13) A pressão exercida pelos pais sôbre os filhos, ou pelos mais velhos sôbre os mais moços recebe a mesma conotação. Os pais tratam bem os filhos e respeitam as opiniōes dêstes; as môças Timbira, refere Nimuendajú, tôdas as vêzes que as mães pretendem tratá-las rudemente ou exigir um matrimônio que lhes desagrada, lembram à genitora a história de Klikwe'i, que se suicidara ao ser espancada pela mãe, que lhe impunha pretendente que não era de seu gôsto. (14)

(12) Id., 1946, p. 113

(13) Id., 1946, p. 113.

(14) Id., 1946, p. 123. 
O ressentimento e o ciúme são considerados despreziveis pelos Timbira. As obrigaçōes do indivíduo para com seu companheiro de classe de idade, de sociedade, ou para com seu parente, impedem-no de expressá-los, assim como impedem a raiva. Sòmente as mulheres, que não pertencem nem a sociedades, nem a classes de idade, isto é, que estão prêsas a menos associaçôes do que os homens, podem exprimir até certo ponto sua raiva, mas sòmente por palavras; e a reconciliação é inevitável, mesmo entre as piores inimigas e rivais, pois a isso as impele a execução de danças em comum no terreiro. Trata-se da atividade do maior interêsse, e mais agradável para as mulheres, indispensável à vida delas, das quais nenhuma pensaria se eximir: "seria inconcebivel para um Timbira ouvir uma mulher declarar que não compareceria à dança da tarde para não encontrar uma rival". (15) Por isso, vêem-se as mulheres compelidas a fazer as pazes umas com as outras.

No entanto, a competição, mesmo exercendo-se ùnicamente através dos grupos e associações, poderia criar um ambiente de rivalidade entre êstes mesmos grupos, atirando-os uns contra os outros, o que seria perigoso, principalmente no caso das competiçōes esportivas. De fato, estas opōem entre si diferentes classes de idade, transformam em adversárias as "metades de estação chuvosa", etc., e poderiam degenerar em rivalidades contínuas. Nestes torneios, todavia, não existem nem vitoriosos nem vencidos (o que é inteiramente incompreensivel para os caboclos brasileiros que habitam a região). Os vencedores não são elogiados, nem os vencidos censurados. A corrida não visa satisfazer vaidades pessoais ou grupais, é antes um fim em si mesma, e o individuo se esforça o mais que pode sem esperar nenhuma recompensa além do prazer de sentir que deu de si a contribuição máxima. Os melhores corredores, embora estimados e gozando de certo prestígio, nāo têm privilégios especiais e em nada se distinguem dos companheiros; "sòmente os preguiçosos, que tentam se furtar a uma corrida, tornam-se alvo de repreensão e caçoadas". (16)

O indivíduo ideal em tal comunidade tinha naturalmente de ser uma criatura pacifica, que foge de disputas, que cede o seu lugar mesmo quando tem a êle todos os direitos, que evita qualquer zanga. " $\mathrm{E}$ considerada uma pessoa má aquela que briga com seus companheiros, que insiste em manter privilégios pessoais, que pugna por reivindicaçōes..." (17) Concordar é a mais alta virtude nesta organização votada ao esfôrço de impedir dissensōes internas. O cerimonial, ao qual ninguém pode deixar de comparecer, força os briguentos a cooperarem uns com os outros, impedindo que as disputas se eternizem. (17)

15) Id., 1946, 119

(16) Nimuendajü, Kurt, 1946, pp. 139 e 140.

(17) Um trabalho muito interessante e que deveria ser felto, é o de analisar muito de perto tóda a estrutura dos Timbira e verificar quais as válvulas de escape e quals as reacó̄es despertadas por um controle aparentemente tấo rígido dos comportamentos. Isto é, de que maneira manifestam os indlgenas as dissensōes, os comportamento de irritaçao, de ódio, de desespero. 


\section{OS MITOS}

O ideal cultural vigente se reflete nos dois tipos de mitos encontrados entre os Tímbira. Se dermos à palavra "mito" uma extensão ampla, englobando contos, histórias, fábulas, casos, etc., ao mesmo tempo que as explicaçōes sôbre os deuses, as origens do mundo e dos homens, - isto é, se incluirmos sob o têrmo "mito", como faz Nimuendajú, êstes dois tipos de narrativas, - encontramos a ambos naquele grupo étnico. Os membros da tribo reconhecem a existência das histórias "dos dias de antigamente" (como dizem), e as histórias de fundo real, que se passaram em tempo não muito longinquo, e cuja data de ocorrência muitas vêzes é ainda mencionada. É possivel, pois, dividir a mitologia Timbira apresentada por Nimuendajú em mitos de passado remoto e mitos de passado recente.

Os de passado remoto, refere Nimuendajú, eram narrados durante as festas de iniciação; são todos de aventuras e explicam, em geral, a origem e a obtenção do cerimonial, que governa a vida dos indigenas, porém sem nenhuma intenção mística ou religiosa. A iniciação dos meninos dura 10 anos e compōe-se de duas cerimônias diferentes, que podem ser repetidas anos seguidos: Ketúaye e Pepyé. Um dos ritos do Ketúaye é a matança de um porco, comido ritualmente por tôda a tribo, menos os iniciandos. Os indigenas passam êsse dia todo a comer e a contar as "histórias de antigamente". (18) Esta cerimônia existe também numa outra festa que nāo pertence à iniciação, a dos Pepkaha'k, ou festa dos guerreiros, a qual, todavia, é uma espécie de recordaçāo ou de imitação, pelos adultos, dos ritos de iniciação. (19) Numa das fases de cerimônia do Pepyé, por sua vez, os iniciandos são levados para longe da aldeia, pintados com urucu e naquela noite não se lhes permite dormir; passam o tempo ouvindo tambèm as "histórias de antigamente", que um velho se incumbe de narrar. (20) Nota-se em todos êstes casos uma intenção educacional visivel, pois as histórias de antigamente se referem quase sempre à origem das festas, das dancas, dos cantos, afirmando-lhes o valor e incentivando o respeito com que devem ser tratados. Parecem destinados a focalizar a atençāo sôbre o cerimonial, em detrimento das outras atividades tribais, pois as danças quotidianas sāo pouco mencionadas e a corrida de troncos - esporte predileto, - não figuram em nenhum dos mitos registrados por Nimuendajú.

As histórias de passado recente surgem a todo momento na narrativa de Nimuendajú, tôdas as vêzes que descreve um costume peculiar ou um comportamento especial dos individuos. Um exemplo é o da história já citada da jovem Klikwe'i, que as Timbira casadoiras lembram às māes, quando estas pretendem coagi-las a uma uniāo pouco de seu gôsto. E quando há um adultério no ar, vem à baila a história de Wohō. A espôsa dêste foi sedu-

(18) Nimuendaju, Kurt, 1946, p. 178.

(19) Id. 1946, p. 212. 
zida pelo famoso guerreiro Karatí, mas Wohō não reage, até que os companheiros de sua classe de idade o reprovam pela falta de coragem. Wohō responde que não lhe falta coragem para se vingar e sim para iniciar uma disputa, o que sempre deve ser evitado por um Timbira; mas uma vez que os companheiros se consideram molestados por sua atitude, dispõe-se a agir. Com efeito, Wohō mata o guerreiro. Os parentes dêstes imediatamente se reunem para vingá-lo, enquanto a familia grande de Wohō também se apresta para defendê-lo. Os chefes intervêm e põem têrmo à disputa, induzindo os parentes do assassinado a aceitarem uma indenização por parte do assassino. (21) Casos como êstes são narrados justamente nos momentos em que se tornam necessários, tendo por fim provocar ou incrementar as atitudes individuais consideradas satisfatórias pela cultura.

A freqüência e a naturalidade com que aparecem êstes contos na narrativa de Nimuendajú, entrelaçados à vida quotidiana, indicam a importância que têm para os indigenas. Garantem tais mitos "a validade dos valôres morais e dos padrōes de comportamento reconhecidos e aceitos pela tribo", para adotarmos a linguagem de Egon Schaden. (21) Refletindo os padröes e valôres do comportamento tribal, exercem primordialmente as funçōes de exemplo e de reforç̧o da conduta considerada a melhor pelos indigenas: a cordura, os sentimentos pacificos, a ligação tio-sobrinha, o tratamento ameno dispensado pelos pais aos filhos, a solidariedade das classes de idade, o castigo do adultério, etc. Se analisarmos, por exemplo, a história de Wohō, atrás relatada, vemos que ela contém todos os característicos da sociedade Timbira: a importância das classes de idade na vida individual dos membros da tribo; a função da familia grande, defensora de seus componentes; a cordura como ideal de comportamento individual; a intervenção moderadora dos chefes, impedindo o prolongamento de uma disputa e terminando-a por uma indenização.

A função dêstes mitos também é educativa, e neste ponto êles se aproximam dos mitos de passado remoto. Mas enquanto os de passado remoto se preocupam em afirmar o valor das cerimônias e em explicar origens, quer dos homens, quer das técnicas, quer das festas, os de passado recente ensinam o comportamento individual e reforçam relaçōes humanas. Podemos, pois, dizer que cada um dos dois tipos de mitos corresponde a um nivel das relaçōes sociais dos Timbira: os de passado remoto ligam-se predominantemente ao nivel grupal, tanto em suas explicações quanto em seus valôres; os mitos de passado recente são conexos com o nível individual, e do mesmo modo dizem respeito às explicações e aos valôres.

Encontramos nos mitos de passado remoto, de maneira profunda, a ressonância das valoraçōes primordiais emprestadas pelos Timbira tanto às coisas sociais quanto às coisas da natureza, - ressonância inegável, embora velada e sutil, como se pode ver no mito do Sol e da Lua. Companheiros

(21) Schaden, Egon, 1946, p. 19, citando K. Th. Preuss. 
de aventuras, resolvem Sol e Lua um dia se separar, e separar também tudo o que possuiam. "Sol escolheu o dia, deixando a noite para a Lua; a Lua insistiu em possuir o dia, mas Sol disse que não lhe competia escolher nada..." (22) Cabendo o dia ao Sol e a noite à Lua, também as coisas se dividiram, na natureza, em duas metades: $k a$ ', relacionada com o dia, ficou com as coisas claras e atu'k, relacionada com a noite, ficou com as coisas escuras. Note-se que, na aldeia, os homens também se dividem em ka'makra e atu'kmakra, de acôrdo com os nomes que lhes vão sendo legados pelos parentes; esta divisão corresponde, na localização das metades na aldeia, à antítese leste-oeste, à qual se liga a oposiçāo Sol-Lua pelo fato do sol nascer a leste e a lua nova a oeste. (23) "Parece muito provável, escreve Nimuendajú, que antigamente o ka'makra se identificava com a metade leste, o atu'kmakra com a metade oeste da aldeia, o primeiro gozando de ascendência-cerimonial durante a estaçāo sêca, o último durante a estação das chuvas". (24)

A relação $\mathrm{ka}^{\prime} / \mathrm{dia} / \mathrm{estação-sêca} \mathrm{e} \mathrm{atu'k/noite/estação-chuvosa} \mathrm{tem} \mathrm{no} \mathrm{fun-}$ do uma valorização incipiente. E durante o dia que se realizam as atividades úteis da tribo, a caça, o plantio, as festas; a noite é inútil, de onde a reclamação da Lua, achando-se lezada quando se vê obrigada a ficar com ela. Também a estação valorizada e importante é a estação sêca, durante a qual podem se desenrolar os festivais que enchem de côr a vida dos Timbira, enquanto a estação chuvosa é de relativa monotonia.

A própria personalidade do Sol e da Lua, assim como as criaçōes a que se entregam, refletem a valorização. Sol e Lua foram banhar-se. Sol mergulhou e voltou à tôna com um rapaz muito bonito; Lua tentou o mesmo, mas o menino que voltou com êle era feio e escuro. De nôvo mergulhou o Sol e voltou com uma mocinha bonita; Lua fêz o mesmo, mas a que o acompanhou era bem feiosa. "Assim continuaram ambos por muito tempo. E é esta a razāo porque existem sêres humanos bonitos e feios, bem formados e aleijados". (25) Quanto ao caráter, Sol é o individuo ideal para a comunidade Timbira: não briga, cede ante os rogos impertinentes e importunos do companheiro, é modesto, quieto, acomodado, não faz valer seus direitos (embora convencido dêles) a fim de não desencadear disputas, pois evita o mais possivel as brigas. Lua é criatura arrogante, exigente, insatisfeita, que insiste em satisfazer tôdas as suas vontades, que rezinga e briga por qualquer coisinha, que impōe a prioridade de seus desejos sôbre os desejos dos outros e que por isso mesmo acaba levando na cabeça e fazendo papel ridiculo; é, pois, o tipo desprezado pela civilização Timbira. (26)

(22) Nimuendajú, Kurt, 1946, P. 245. E interessante notar que há aqui uma referencla a uma imposicão do sol sobre a Lua, rugindo ao precelto Timbira habitual padrío valoratercer pressão sobre ninguém. O estudo destas discordanclas com o

(23) Nimuendaju, Kurt, 1946, p. 84 .

(25) Nimuend p. 86 .

(25) Namuendajú, Kurt, 1946, p. 244. 
Em tal valorização, reflete-se o estilo de vida da comunidade, tôda orientada para a harmonia interna. Mas a valorização pode ter duas interpretaçōes: Sol e Lua personificam as fôrças morais que agem na sociedade Timbira, tornando-as mais palpáveis e mais fáceis de impressionar; ou representam, para os indigenas, os aspectos da natureza "que são de importância para o bem-estar da sociedade", mas tão fortemente se acham os Timbira imbuídos da ordem social em que vivem, que enxergam o Sol e a Lua sujeitos às mesmas fôrças morais que nela influem. De qualquer maneira, o mito do Sol e da Lua indica muito bem de que maneira as coisas da natureza afetam a vida social (a utilidade do dia, a preferência pela estação sêca), ligando-se a elas, de maneira compreensivel, os valôres morais que imperam na tribo (por exemplo, o bom caráter do Sol, o qual por sua vez comanda o dia e a estação sêca), tudo ápresentando sempre um aspecto nitidamente educativo.

Embora personalizados, Sol e Lua não podem ser chamados de heróis civilizadores, se aceitarmos para definição dêstes a de Van Deursen: "Ente mitico, ao qual se atribuem podêres sobrenaturais e que ou desempenhou um papel importante na transformação da terra depois da criação ou do dilúvio, ou então deu à tribo importantes leis, instituiçōes, bens de cultura". (27) Nada disso fizeram Sol e Lua; só se lhes pode atribuir a criação dos sêres humanos, aos quais nada deram como técnica ou como leis, não se imiscuindo na organização tribal. muendajú; de acôrdo com êstes, Sol e Lua seriam heróis ou deuses criadores, mas não civilizadores. possivel que uma análise mais profunda, ou que o registro de novos mitos, mostre aspectos dos dois heróis que, em nossa análise, passaram desapercebidos, e que os classifiquem naquela categoria.

Existe, porém, entre os mitos Timbira, reproduzidos pelo grande etnólogo alemão, um que corresponde à definição de herói civilizador - "heroina" neste caso, pois trata-se de Kacetiwe'i, a môça-estrêla. Tukti, por ser muito feio, não encontrava mulher; uma estrêla se compadece dêle, vem para a terra consolá-lo, transformada na môça Kacetiwe'i, e com êle se casa. Ora, nêsse tempo os índios nāo conheciam plantas cultivadas e comiam paus podres com a carne. Kacetiwe'i encontra espigas de milho perto do riacho e mostra aos indios que aquilo é comestivel; ensina-os a plantar e colher o milho, a socá-lo no pilāo, a fazer bolos de fubá. "Kacetiwe'i poderia ter revelado ainda outros segredos ao marido, se êste não insistisse em cohabitar com ela. Por causa disto, decidiu voltar para o céu. Tukti pediu-lhe que o levasse junto, pois não conseguiria arranjar outra espôsa. Tôdas as mulheres choraram com a resolução de Kacetiwe'i. De noite ela foi para o terreiro e começou a cantar; quando a manhã chegou, ela e Tukti tinham desaparecido da terra". (28)

(27) Schaden, Egon, 1946, p. 24, citando Arie Van Deursen.

(28) Nimuendajû, Kurt, 1946, p. 245. 
Quando noutros mitos os Timbira aprendem novidades, como danças ou outras atividades, ou quando adquirem instrumentos que não possuiam, é sempre ou por imitaçáo, ou por roubo. Kacetiwe'i é o único personagem sobrenatural, dentre os citados por Nimuendajú, que vem à terra, vive junto com os indios, ensinando-lhes coisas novas, retirando-se antes de ter dado à tribo todos os beneficios de que possuia o segrêdo. Mulher, Kacetiwe'i ensina coisas de agricultura e de cozinha, atividades que entre os Timbira sóem ser desempenhadas pelas mulheres. Seria interessante investigar, nas tribos possuidoras de mitos de heróis civilizadores, até que ponto o fato dêstes serem sempre masculinos se liga à maior valorização do homem em relação à mulher pela cultura tribal, - o que não se nota entre os Timbira. Pois segundo observou Nimuendajú, entre êstes tanto homens quanto mulheres são respeitados e reconhecidamente possuem o mesmo valor.

Mais uma vez, cumpre ressaltar o aspecto fortemente educativo dos mitos Timbira registrados por Nimuendajú; seu papel de fator de contrôle social é também evidente. Numa organização predominantemente voltada para a harmonia interna e a concórdia, como parece ser esta, a mitologia constitui um instrumento a serviço dos objetivos mais valorizados pela civilizaçāo do grupo.

\section{ANALISE, SINTESE}

Descrever apenas não basta aos estudiosos dos fatos sociais; precisam sempre ir mais longe, buscar interpretaçōes e explicaçōes. Daí a necessidade de, uma vez analisados certos aspectos da cultura, tentar estabelecer correlaçōes: depois de estudar separadamente organizaçāo social e mitos, aproximá-los para ver como se ajustam e como funcionam engrenados. $\mathrm{Na}$ civilização Timbira, como acabamos de ver, organização social e mitos visam o incremento da coesão interna das tribos.

E por que motivo se teriam organizado os Timbira de maneira a evitar todo conflito intra-tribal e a fortificar os laços entre individuos e grupos? Uma hipótese explicativa só pode ser buscada tentando uma análise noutro nivel, o nivel das tribos Timbira como um todo. Assim, depois de analisar a tribo, como unidade, passamos para outro nivel, que se poderia chamar da sociedade global Timbira.

Há evidente correlação entre a forte coesão interior e a vida de lutas das tribos Timbira umas com as outras. Estão em constante pé de guerra; os Krēyé de Bacabal, em reecontros sangrentos contra os Ramkō'kamekra e os Cakamekra; os Krêyé de Cajuapára, inimigos dos Krikati; os Pukóbye, conhecidos por sua ferocidade; os Gaviōes, hostís a tôdas as tribos habitando em suas redondezas; os Krahō em lutas com os vizinhos; os Apa'nyekra em guerra contra os Ramkō'kamekra e assim por diante. (29) Não podem, pois,

(29) Nimuendajú, Kurt, 1946, p. 15 a 31. 
permitir estas diversas tribos que no seu interior ocorram disputas graves, pois um grupo internamente minado por ressentimentos não pode opor frente coesa ao ataque inimigo. A colonização portuguêsa parece pouco ter alterado êste estado de coisas devido ao aspecto de luta de que se revestiu contra os Gê; apenas aumentou o número de adversários das tribos Timbira, que atualmente não combatem sòmente entre si, porém também contra os caboclos da região.

Estado de luta que se relaciona, por sua vez, com o tipo de território ocupado por êste povo. Planícies semi-áridas e capoeiras formam a maior parte das terras Timbira. As florestas, de significado económico importantíssimo para êstes indios, pois oferecem, além do único tipo de solo adequado à sua agricultura, os frutos indispensáveis de burití e de babaçú, assim como a caça (que quase não existe nos cerrados), são encontradas, pouco numerosas, ao longo dos ribeirōes maiores e dos rios. As tribos lutam, pois, entre si pela conquista ou pela defesa dêsses territórios, que asseguram o bem-estar dos individuos.

A cultura Timbira apresenta, então, dois aspectos diversos conforme a encararmos pelas relaçōes intra-grupais, ou pelas relaçōes inter-tribais. Enquanto as relaçōes dentro da tribo são dominadas pela preocupação constante de garantir a paz e a harmonia internas, evitando tôda a disputa e tôda a rivalidade, as relaçōes das tribos umas com as outras se caracterizam pela hostilidade e disputa permanentes.

Há, assim, entre o meio, a sociedade global, os grupos sociais, os individuos, interação que leva à formação de configuraçōes sociais diversas, visando a adaptação dos grupos tanto a um meio determinado como a uma sociedade global, e também a adaptação do individuo aos grupos e à sociedade global em que vive. Só a visão total do conjunto permite chegar a compreensão de um grupo particular dentro do todo, assim como da hierarquia de valôres que nêle é dominante. A compreensão de uma parte da cultura Timbira - dos mitos, por exemplo, - só se alcança plenamente quando colocada funcionando dentro da tribo em que existe, e relacionada com a organização desta. Porém a organização tribal, por sua vez, só é compreendida quando a encaramos dentro do complexo formado pelas diferentes tribos e pelo território em que habitam. Se a análise nos mostra "o que é" e "como é", só a sintese pode responder ao "porquê". Instrumentos do estudo sociológico, - como o são também nas outras ciências, - análise e síntese correspondem a dois momentos diferentes do trabalho, à descrição e à interpretação.

\section{REFLEXÃO FINAL}

Voltando ainda aos mitos, um estudo interessante a ser efetuado seria o da emoçāo artística, existente ou nāo, em quem narra e em quem ouve. O problema se colocaria da seguinte maneira: além das funçōes educativas e 
de contrôle social que percebemos nos mitos Timbira com relação à organização tribal interna, despertarão êles também entre os indigenas a emoção que entre nós é rotulada de "estética"? No trabalho de Nimuendajú, de que o autor deliberadamente afastou tudo quanto fugisse à mais estrita objetividade, compreendida num sentido quase de registro de atividades ou de ocorrências plenamente palpáveis, não há dado algum que permita uma indicação a respeito. Por outro lado, não existem entre os Timbira os contadores profissionais de histórias; os mitos são narrados por velhos no momento da iniciação, ou em ocasiốes adequadas, não se sabendo a qual dos velhos e por que razäo cabe narrá-los. Se existissem contadores profissionais, já se poderia aventar a hipótese de que a história e contar histórias constituiria arte, pois tais contadores são como que os precursores dos comediantes. No entanto, o texto dos mitos que classificamos de "passado remoto", a complicação das aventuras, a trama das peripécias, dão a impressāo de "livre expansão de uma atividade criadora", à qual se conjugariam sentimentos de plenitude e de alegria, - emoçōes que segundo certos autores constituem um dos climas da criação da obra de arte. (30) Mas o que é verdade entre nós, sê-lo-á também para os indigenas? ou a criação, entre êles, se processará de maneira diversa? Possuirá, por sua vez, a obra de arte no mejo indigena as mesmas funçōes que Lalo atribui à obra de arte no mundo ocidental, isto é, ser a expressão da sociedade, uma técnica para esquecer, uma reação contra a sociedade, um jôgo à sua margem? (31)

Bis um conjunto de questōes despertadas pela qualidade dos textos da mitologia Timbira, porém que não temos meio algum de aprofundar. Aliás, entre as atividades primitivas, a estética tem sido provàvelmente a menos estudada. O estudo dos mitos e de sua função dentro da organização social seria provàvelmente um dos caminhos que poderia levar até aquêles problemas.

\section{OBRAS CTMADAS}

BASTIDE, Roger - Arte - Socledade, Llvr. Martins Ed., S. Paulo, 1945.

NIMUENDAJ0, Kurt - The Eastern Timblra - University of Callfornia Press, 1946.

SCFADEN, Egon - Ensalo Etno-Sociologico sobre a Mitologia Herbica de Algumas Tribos Brasilelras - Faculdade de Fllosofia, Clencias e Letras, Universidade
de S. Paulo, 1946.

(30) Bastide, Roger, 1945, p. 60

(31) Bastide, Roger, 1945, p. 49 , citando Charles Lalo. 